\title{
Recuerdos de mi padre
}

\author{
José Belaunde Moreyra
}

Para mí es motivo de gran satisfacción que se celebre el centenario de Mercurio Peruano, porque yo colaboré en mis años mozos en su publicación, principalmente como corrector de pruebas. Cuando yo tenía 12 años, mi padre me hizo aprender mecanografía, habilidad que me ha sido después utilísima. Su propósito era que yo le sirviera como secretario y me familiarizara de paso con su pensamiento e ideales.

En verano solía acompañarlo a la imprenta Lumen, donde se imprimía la revista. Quedaba en la calle Pescadería, al costado de Palacio de Gobierno, entre la Plaza de Armas y la Estación de Desamparados. Ahí yo me familiaricé con el sistema de linotipos de plomo que se usaba entonces, y cuyas máquinas eran sumamente ruidosas.

En esta ocasión, yo quiero ocuparme del tema de la fe de mi padre, que es un aspecto poco tocado cuando se habla de él, pero que constituye uno de los principales aspectos, si no el más saltante, de su personalidad y de su actividad, sin el cual su vida y obra serían inexplicables. Creo también que este es el aspecto de su vida por el cual él más desearía que lo recuerden.

En el libro de los Proverbios leemos: "Instruye al niño en su camino y aun de viejo no se apartará de él» (Pr. 22: 6). Desde la primaria hasta cuarto año de secundaria, mi padre estudió en el pequeño colegio que dirigía en Arequipa el sacerdote redentorista francés Hipólito Duhamel. Innumerables fueron las veces en que de niño oí hablar a mi padre de este sacerdote, cuyo retrato colgaba en casa en la pared de la biblioteca (la que daba hacia la avenida que hoy lleva su nombre). No recuerdo con suficiente claridad las muchas anécdotas que relataba de esos años escolares como para poder repetirlas hoy, pero sí se ha grabado en mi memoria el elogio que él hacía de los hábitos de disciplina y de estudio, del amor a la cultura, y de la piedad, que le fueron inculcados en esas aulas.

¡Qué enorme influencia puede tener un educador sabio y santo! ¡Cuántas habrán sido las vidas que fueron temprana y decisivamente marcadas por las enseñanzas de ese sacerdote! ¡Cuántos los hombres que, quizá como mi padre, durante un tiempo se alejarían de la fe, pero que un día, habiendo sido sólidamente instruidos de niño, volverían en la madurez a las verdades imperecederas. No hay obra más bendita que la de enseñar a la infancia los caminos de Dios, porque quien anduvo temprano en ellos, aunque por la soberbia de la vida pueda temporalmente abandonarlos, cuando las pruebas toquen a

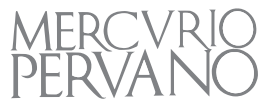


su puerta, la nostalgia por la seguridad que ellos comunican lo impulsará a buscarlos nuevamente.

Mi padre perdió la fe cuando entró a la Universidad de San Marcos. Influenciado por el positivismo entonces en boga se convirtió en un agnóstico. La filosofía reemplazó a la religión. Pero la soledad y las penurias del exilio ablandaron la costra de autosuficiencia e indiferencia que el éxito y las pasiones habían hecho crecer en su alma. La suya no fue una conversión dramática. Fue un retorno gradual y reflexivo a casa, a la certeza de la fe que yacía dormida, pero que no había sido enteramente desechada.

Una vez tornado a ella, la oración, la meditación y la recepción frecuente de los sacramentos, así como la experiencia vivida de la protección y de la guía de Dios en circunstancias difíciles, hicieron que su fe se fuera fortaleciendo hasta convertirse en una roca, en verdad en la columna vertebral de su vida, en torno de la cual se articulaban todos sus trabajos y actividades.

Dos fueron los pilares de la vida de fe de mi padre. El primero, la misa y la comunión diarias, a las que se habituó muy pronto y que no abandonó hasta el final de sus días. Desde los 8 años, en que hice la primera comunión, hasta los 12, en que entré al colegio de los jesuitas, fue mi costumbre acompañar diariamente a mi padre a la misa de las seis y media de la mañana en la parroquia de los padres pasionistas, que, por un designio de la Providencia sin duda, quedaba al lado de la casa.

Mi padre ayudaba con frecuencia a la misa, cuando no lo hacía yo, y, una vez terminada, permanecía largo rato arrodillado dando gracias. La fotografía que un día publicó la revista Caretas, en la que se ve a mi padre en el reclinatorio, con la cara hundida en las manos, transmite perfectamente lo que era su actitud de recogimiento después de comulgar en misa.

Durante esa época, mi padre estaba muy preocupado por su vesícula biliar. Le habían dicho que ya no funcionaba apropiadamente y que habría necesidad de extirparla. La idea de una operación lo horrorizaba, santo temor por el bisturí que yo comparto.

Le habían recomendado tomar diariamente, y en ayunas, una infusión de hojas de boldo, un buen rato antes del desayuno. Para poder cumplir con esa prescripción sin dejar de comulgar ni retrasar la primera colación del día, llevaba a la iglesia una botellita algo chata, como de un palmo de tamaño, llena de la infusión rojiza. Minutos después de comulgar se acercaba discretamente a un confesionario cercano que no estuviera ocupado y allí, semioculto en el reclinatorio del penitente, empinaba el codo hasta apurar el contenido de la botella, posiblemente ante la mirada asombrada de algunas de las personas piadosas que se encontraban cerca. Debo confesar que yo como niño me sentía incómodo de lo que pudieran pensar. ¿Cómo decirles que era boldo y no alcohol? Pero mi padre se cuidaba poco de lo que pensara la gente. 
El segundo pilar eran las dos horas que dedicaba a la oración, lectura y meditación cada noche. Durante los primeros años de su exilio había adquirido el hábito de despertar en la madrugada y no volverse a dormir sin leer largo rato. Mal hábito ocasionado por el insomnio que se convirtió para él, después de volver a la fe de su infancia, en una fuente de luz y consuelo, cuando a la lectura añadió la oración y la meditación.

No podemos saber cómo oraba durante esas vigilias, pero sí le oí decir muchas veces que en esas horas de diálogo con Dios había hallado en innumerables ocasiones consuelo en la adversidad y luz en la incertidumbre, y que, gracias a ella, había tomado muchas decisiones importantes sobre los asuntos que tenía entre manos. Apasionado de los salmos, él debe haber comprobado la verdad que encierran estas palabras de David:

\section{Bendeciré al Señor que me aconseja;}

aun en la noche me enseña mi conciencia. (16: 7)

¿Qué leía él? Si hemos de guiarnos por los libros que se apiñaban sobre su mesa de noche, en primer lugar, la Biblia, la Imitación de Cristo, y también el Kempis agustiniano (una preciosa selección de pasajes entresacados de las obras del obispo de Hipona, sobre todo de sus sermones, y arreglados por temas con tanto acierto que parecería que el santo los hubiera escrito ex profeso en ese orden); además de las obras de santa Teresa, san Juan de la Cruz, los Ejercicios de san Ignacio, etcétera.

Él poseía un ejemplar de la Biblia del abate Crampón, la primera traducción católica hecha al francés directamente de los originales hebreo, arameo y griego (esto es, no de la Vulgata latina) publicada a finales del siglo XIX, famosa en su momento por sus eruditas notas, y que fuera reeditada muchas veces. El manoseado ejemplar lleva las huellas de haber sido muy leído. Las páginas marcadas con lápiz nos pueden dar una idea de cuáles eran los libros de las Escrituras que él prefería. Además de los evangelios, son los salmos y el profeta Isaías los más marcados.

Mi padre rara vez subrayaba versículos. Más bien solía trazar una raya vertical a lo largo de los pasajes que le llamaban la atención y a veces anotaba al margen algunas palabras de comentario, desgraciadamente casi todas ilegibles. Deduzco que los pocos versos subrayados deben haber tenido para él un significado especial. Doblemente subrayada, por ejemplo, esta frase del salmo 25 tiene el carácter de una confesión personal:

De los pecados de mi juventud no te acuerdes, ni de mis trasgresiones.

Dos líneas del salmo 30 marcadas con un trazo rápido expresan sin duda una verdad acerca de Dios en la cual él hallaba consuelo: 
Porque su cólera dura un instante, pero su gracia toda la vida.

El versículo siguiente del salmo 37 expresa un pensamiento cuya verdad quizá él había comprobado por experiencia:

Los mansos poseerán la tierra, gozarán de las delicias de una paz profunda.

Esa es la paz a la que todos aspiramos, pero que solo Dios puede dar. Para mí es sintomático que él haya subrayado con cuidado las palabras iniciales del salmo 41:

Bienaventurado el que piensa en el pobre...

Pues muchas veces me asombró de muchacho la paciencia con que él atendía a los necesitados que venían a importunarlo en las horas que dedicaba al estudio en la mañana. Viudas sin trabajo, padres en busca de una recomendación para colocar a un hijo, enfermos que requerían ayuda para algún tratamiento... Cuanto más humilde la persona, con mayor cortesía y solicitud la trataba.

Pero su caridad era sobre todo práctica y eficiente. Más de una vez lo vi partir con el hombre o la mujer que buscaba trabajo para recorrer ministerios y oficinas públicas hasta encontrar el puesto apropiado. Claro está que la posición que él ocupaba y su prestigio le abrían todas las puertas. ¿Quién le hubiera negado un servicio? Si lo había, su don de persuasión y su cordialidad vencían las resistencias.

Poco después de la muerte de mi padre, se acercó a mi casa una señora que, en recuerdo de su memoria, se ofreció a cuidar gratuitamente a nuestros hijos las noches en que por algún compromiso mi mujer y yo tuviéramos que salir. Nos contó que años ha mi padre no había descansado toda una mañana hasta encontrarle un trabajo en el Jurado Nacional de Elecciones, y que este puesto la había salvado a ella y a sus dos hijos del hambre cuando enviudó.

En otras ocasiones, mi padre se dirigía directamente al médico apropiado para pedirle que atendiera a la persona que le enviaba con una tarjeta. Creo que en esos casos él corría por lo menos parcialmente con los gastos que demandara el tratamiento.

Con el correr de los años, mi padre fue adquiriendo una humildad verdaderamente evangélica, espontánea, profunda y no fingida, que se manifestaba no solo en la vida diaria sino también en circunstancias en las que lo contrario hubiera podido parecer lo indicado.

Se sabe que los peruanos tenemos una especial afición -aunque el gusto se va perdiendo- por las actuaciones públicas. Toda ocasión parece buena para organizar una ceremonia y, si no la hay, se la inventa. En los años finales de la vida de mi padre parecía como que toda institución que quisiera organizar alguna actuación pública escogía como pretexto tributarle un homenaje. El anuncio de que él iba a hacer uso de la palabra aseguraba la afluencia del público. 
Y ahí estaba él, sentado frente al público en el estrado, mientras los oradores se sucedían exaltando aspectos diversos de su obra y de su vida. Me admiraba la naturalidad exenta de toda vanidad con que mi padre soportaba la avalancha de elogios que le dedicaban mirando al suelo. Solo cuando la alabanza alcanzaba un tono demasiado subido se encogía incómodo en su asiento.

Él soportaba estos ritos de nuestra vida pública como una especie de obligación propia de su posición, pero también como una ocasión para echar al viento las ideas que su mente infatigable engendraba continuamente y que él transmitía con esa elocuencia suya que encandilaba a los oyentes.

Recuerdo una ceremonia pública en Arequipa, a la que asistí siendo chico, en la que después de un discurso algo tedioso, cuando mi padre se dirigió al estrado, uno de los asistentes que se apretujaba a mi lado le dijo a su vecino: "Ahora viene lo bueno". Cuán cierto es que el hombre se deleita en la palabra bien hablada.

Pero la humildad no le vino fácilmente, pues él era orgulloso por naturaleza y petulante; incluso arrogante cuando la ocasión lo tentaba. Como él mismo nos contaba, desde el colegio le gustó ocupar siempre el primer lugar. En verdad difícilmente soportaba una posición que no fuera la primera.

Gran conversador, le placía ser el centro de los cenáculos y dominar la conversación con el brillo de su ingenio. Cuando por algún motivo esto no ocurría, o la cortesía lo obligaba a ceder el centro de la escena, se aburría y difícilmente lo disimulaba.

Pero pese al predominio que le gustaba ejercer en la conversación era cortés en el diálogo y dejaba espacio para la réplica. Ciertamente en ocasiones tendía a abrumar con su elocuencia al que lo contradecía, pero por lo general se retenía consciente de su superioridad en la polémica. Sin embargo jcuántos resentimientos puede él haber causado entre los que se sentían opacados por la superioridad de su inteligencia!

Creo que sus discípulos de sus últimos años podrían dar fe del interés con que él los escuchaba exponer sus ideas y de cómo él los estimulaba a desarrollarlas independientemente.

Ciertamente la intimidad con Dios hace al hombre por necesidad humilde. Acostumbrado a la compañía de los grandes de este mundo, mi padre no rehusaba el trato con los humildes. Si bien él sabía llevar con prestancia, cuando la ocasión lo requería, la dignidad de su cargo, no se aferraba a los signos exteriores de su posición encumbrada. Prescindía de ellos cuando la situación no los exigía.

Al regresar de Europa ya casado, mi mujer y yo nos instalamos con nuestros hijos en la casa que mis padres tenían en Chosica y donde mi padre solía pasar fines de semana largos cuando no estaba en Nueva York. Al comienzo yo no tenía necesidad de bajar a Lima todos los días, pero, aun cuando yo no tuviera necesidad de hacerlo, venía a Lima en el pequeño Fiat 600 que tenía entonces, solo para traer a mi padre.

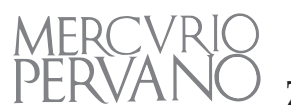


Pero pronto él se negó a imponerme esta incomodidad. Tampoco le gustaba incomodar al chofer de casa haciéndolo venir a Chosica solo para buscarlo, ni privar a mi madre del automóvil durante algunas horas. Entonces se venía a Lima en colectivo o en micro.

Colmado de escrúpulos y de temores, yo lo acompañaba al paradero cargando su maletín lleno de documentos y él se paraba en la esquina a esperar el próximo carro como cualquier hijo de vecino. Luego subía al primer vehículo que pasara donde hubiera un asiento vacío, ante el asombro de los pasajeros que lo reconocían. En esa época, aparte de los ómnibus que él evitaba por lo duro de sus muelles, hacían la ruta de Chosica las primeras combis de la marca Volkswagen, así como también taxis viejos convertidos en colectivos.

A mí me torturaba el temor de que algo pudiera pasarle en la carretera, porque los accidentes eran frecuentes y sabíamos, por lo ocurrido al guardián de la casa, que las consecuencias de un choque podían ser graves. Pero él no tenía ningún temor. Sabía que el Señor lo cuidaba. Había hecho suyo ese verso del salmo 91 que dice:

Porque Él ordenará a sus ángeles que te guarden en todos tus caminos y ellos te llevarán en sus manos para que tu pie no tropiece en piedra.

Esa confianza en la protección de Dios y la convicción que proporciona el convencimiento de poseer la verdad le daban un gran coraje para enfrentar situaciones riesgosas. Todavía recuerdo la disertación que mi padre pronunció en San Marcos en 1944, con la que inauguró un ciclo de conferencias organizado por la Sociedad Peruana de Filosofía. Sus amigos le habían advertido que era una imprudencia de su parte, porque los marxistas habían protestado contra su presencia en el claustro sanmarquino y estaban preparados para impedir que hablara. Cuando mi padre se dirigió al púlpito del Aula Magna para iniciar la conferencia, empezaron también los gritos, las interrupciones y las preguntas desafiantes. Mi padre no se arredró por la oposición, que él esperaba, sino, al contrario, habló con más fuego, sin dejarse interrumpir, ocasionalmente contestando a los cargos que le hacían, o apostrofando a sus adversarios. Los tomates y los huevos empezaron a volar, pero ninguno dio en el blanco. Una mano invisible parecía desviarlos. La actitud decidida de mi padre desconcertó a sus opositores y alentó a sus partidarios. Por último, los perturbadores se cansaron. El triunfo de mi padre fue tanto más resonante como humillante la derrota de sus enemigos. Al final, después de una larga ovación, fue sacado en hombros. Días después se organizó en la Universidad Católica un homenaje de desagravio.

La biografía espiritual e íntima de mi padre está todavía por escribirse. Si alguien acometiera esa tarea, haría un gran servicio a la juventud de esta generación y de las generaciones futuras. Podrían contemplar el modelo de un peruano universal, que fue a la vez un estudioso de nuestra sociedad y de 
nuestra historia, un maestro universitario y un hombre público, un verdadero cristiano que no se avergonzó de su fe y un gran patriota que sirvió a su país con desinterés en la defensa de sus fronteras, y contribuyó a su prestigio externo en los foros internacionales.

Llevado muy joven por la necesidad de ayudar a su familia, entró a trabajar a los 16 años en el Archivo de Límites de la Cancillería en una época en la que la política exterior peruana estaba dominada por el tema de la fijación de nuestras fronteras. Convertido en el especialista de un tema crucial, pero árido, su acuciosidad y prodigiosa memoria lo convirtieron, primero, en el asistente indispensable, y luego, en el negociador y abogado más versado de la causa peruana. Sin embargo la meta de su vida era consagrarse a la carrera universitaria. Nunca ambicionó ser diplomático. Yo creo que fue la Providencia, cuyos "caminos no son nuestros caminos", la que lo llevó al lugar donde no solo podía servir mejor a su país, sino también, haciéndolo, alcanzar rápidamente prominencia, y desde allí ser utilizado para sus propósitos ulteriores.

Pocas personas como él han cultivado con tanta generosidad la amistad. Para gran suerte suya nunca conoció la envidia. Era celoso ciertamente de sus derechos y atribuciones, pero era generoso en prestar su colaboración. Admiraba sin mezquindad las cualidades de sus amigos -entre los cuales se contaban los hombres más brillantes de su generación- sin dolerse de que alguno pudiera echarle sombra.

Alentó y guio a sus discípulos que destacaban, en la esperanza de que muchos prosiguieran la obra que él y otros estudiosos habían iniciado. Se prodigaba en consejos y compartía sus conocimientos y las fuentes de información que poseía sin mezquindad.

Llevó una intensa vida pública, en la que asumió grandes responsabilidades en momentos cruciales en los cargos que le tocó ocupar. Gozó de las compensaciones que dan el éxito y la fama, pero también padeció las amarguras y vicisitudes que causan la oposición celosa y las intrigas.

Sin ser frívolo en su conversación, era brillante en sociedad. Era ciertamente un hombre de mundo, como lo exigía su profesión y la posición que ocupaba; pero el reverso de esa cara brillante externa fue su vida interior profunda, hecha de oración, lecturas y meditación a la que me he referido antes, en las que encontró las luces y la fortaleza que necesitaba.

Tenía siempre la palabra justa y elegante en los labios, en el momento apropiado para disolver tensiones, zanjar diferencias y aplacar los ánimos. La espontaneidad de su afecto y la cordialidad de su sonrisa desarmaban los temperamentos más gélidos. Era, en verdad, un diplomático nato.

Todavía recuerdo las sesiones de la comisión de la Asamblea de las Naciones Unidas, a fines de 1949, que le tocó presidir y a la que se había encomendado tratar el tema álgido del conflicto árabe-israelí. En muchas ocasiones, cuando parecía que los delegados enemigos se iban a ir a las manos, una oportuna intervención

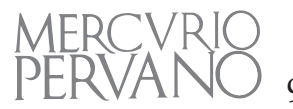


suya calmaba los ánimos y atenuaba la tensión del ambiente, y permitía que el debate prosiguiera en términos civilizados. Recuerdo especialmente una de las sesiones finales, particularmente caldeada, en que su conducción del debate fue tan hábil y brillante que cuando cortó la discusión con una maniobra oportuna, y evitó un violento enfrentamiento, todos los presentes, delegados y público, prorrumpieron en una ovación cerrada a mi padre. Hecho inusual ciertamente, que quien preside la sesión sea el que coseche los mayores aplausos.

La personalidad de mi padre me recuerda al personaje bíblico de Nehemías. Copero (esto es, ministro) e íntimo del rey Artajerjes, Nehemías era un cortesano familiarizado con los caminos del poder, con el ceremonial y el lujo de la corte, así como inevitablemente también con sus intrigas. Pero, al mismo tiempo, era un hombre de fe y oración que intercedía incesantemente ante Dios por la restauración de su pueblo. El libro del Antiguo Testamento que lleva su nombre consigna varias de las oraciones que él elevaba al Altísimo.

Dios usó la influencia que Nehemías llegó a alcanzar ante su soberano para obtener el apoyo y los medios necesarios para reconstruir las murallas de Jerusalén, demolidas durante la invasión babilónica.

A semejanza del patriota y hombre público judío, Dios llevó a mi padre a la cúspide de la carrera diplomática en su propio país y en los foros internacionales, no solo para orgullo de su patria, sino también para ponerlo como testigo de la fe cristiana. No creo que mi padre pronunciara un solo discurso en los escenarios mundiales sin mencionar a la Providencia y a su intervención en los asuntos humanos, o sin insistir en que los principios morales del Evangelio deben regir las relaciones internacionales.

No faltaba algún delegado escéptico a quien esa característica suya irritara, pero su versación jurídica y el brillo de su elocuencia, además de la gentileza de su trato, le habían ganado tal prestigio entre los delegados a las Naciones Unidas, así como también entre los funcionarios y empleados de la organización, que estaba a cubierto de ataques malévolos. No solo lo apreciaban los delegados de las potencias occidentales, y los de los países árabes y los de Israel, sino también aquellos con los que con más frecuencia polemizaba, los de la Unión Soviética y del bloque socialista. Soy testigo del afecto que por él sentía Vishinsky, el ardoroso diplomático ruso que encontró en mi padre a un contrincante a la altura de su talento.

Cuando falleció de improviso al término de un día atareado en que pronunció dos discursos, uno en la mañana y otro en la tarde, la noticia de su muerte inesperada consternó a todos. La asamblea interrumpió al día siguiente sus trabajos y dedicó las dos sesiones, matinal y vespertina, a rendirle homenaje; bien grande fue el número de los delegados que pidieron usar la palabra.

Sus funerales en Lima fueron una verdadera apoteosis. Una enorme masa de gente acompañó al féretro desde Torre Tagle, donde había sido velado, hasta la Catedral. Durante más de una semana, los diarios y las revistas de la 
capital no cesaron de publicar artículos y reseñas sobre su obra y sobre su vida, escritos algunos de ellos por personas que nunca sospeché se contaran entre sus admiradores.

Creo que la atracción que ejercía mi padre sobre el pueblo, él que nunca ejerció el poder político, era de naturaleza espiritual. No solo procedía de la percepción de su superioridad intelectual, sino sobre todo del impacto de su calidad moral, de su virtud cristiana que el pueblo instintivamente reconoce, y a la que otorga su confianza. Aunque no podemos negar el carácter innato de las condiciones que cada ser trae consigo, la fruición de las mejores cualidades es algo que Dios otorga a quienes se acercan a Él y lo buscan de todo corazón.

Quisiera por ello terminar esta corta semblanza de mi padre citando unas frases del salmo 92 que creo le son aplicables:

Bienaventurado el hombre que teme al Señor,

$y$ en sus mandamientos se deleita en gran manera.

Bienes y riqueza hay en su casa

y su justicia permanece para siempre.

El hombre de bien tiene misericordia y presta;

gobierna sus asuntos con prudencia,

por lo cual no resbalará jamás.

En memoria eterna será tenido el justo.

La última frase de ese texto evoca el más allá, la vida futura; pero tiene también una resonancia presente. Yo creo que la vigencia actual de la obra de mi padre, el recuerdo constante de su memoria, da fe de lo adecuadas que son esas palabras aplicadas a él. 